\title{
Phosphate-based treatments for conservation of stone
}

\author{
Enrico Sassoni ${ }^{a^{*}}$ \\ ${ }^{a}$ Department of Civil, Chemical, Environmental and Materials Engineering, University of Bologna, Via Terracini 28, 40131, Bologna, Italy \\ Received: 30 May 2017 / Accepted: 09 August 2017 / Published online: 9 October 2017 \\ (C) The Author(s) 2017. This article is published with open access and licensed under a Creative Commons Attribution 4.0 International License.
}

\begin{abstract}
To overcome the limitations of currently available protectives and consolidants for carbonate stones (such as marble and limestone), in 2011 the use of calcium phosphate was proposed. The idea is forming calcium phosphates (ideally hydroxyapatite) as the reaction product between the substrate and an aqueous solution of a phosphate salt that the stone is treated with. In this paper, the studies aimed at identifying the best treatment conditions (in terms of nature and concentration of the phosphate precursor, solution $\mathrm{pH}$, reaction time, ionic and organic additions) are first briefly summarized. Then, the efficacy of the phosphate treatment in protecting marble from dissolution in rain and restoring cohesion of weathered marble and limestone is discussed. Some recent studies on the use of the phosphate treatment on alternative substrates and some future steps for research on the topic are finally outlined.
\end{abstract}

Keywords: Cultural heritage; Marble; Hydroxyapatite; Protection; Consolidation

\section{Introduction}

A great part of cultural heritage objects (e.g. monuments, architectural decorations and statues) is made of carbonate stones, such as marble and limestone [1]. These two stone types have basically the same composition (up to $100 \%$ calcite), but differ in terms of microstructure (the open porosity being close to $0 \%$ for marble and up to $50 \%$ for limestone). Consequently, they suffer from different deterioration processes, mainly dissolution in rain [1] and thermal weathering [2] in the case of marble and stress from crystallization of ice and salts in pores [3] in the case of limestone. Unfortunately, the commercial products that are currently available are not fully satisfying in terms of:

- Protecting action. Protection is intended as the ability to reduce stone dissolution in rain, by formation of a surface hydrophobic layer (which is typically the case of organic protectives) or by formation of a surface layer with reduced solubility (which is typically the case of inorganic protectives). However, organic products (e.g. acrylic resins) generally lack compatibility and durability, because they dramatically alter stone transport properties and they are highly sensitivity to UV, temperature variations and biodeterioration [4]. Inorganic products (e.g. ammonium oxalate) exhibit a better compatibility but still have a reduced efficacy [5].

- Consolidating action. Consolidation is intended as the ability to improve cohesion in weathered stone and improve mechanical properties, by providing a binding action between the stone grains. Organic products are effective in improving mechanical properties, but again they lack compatibility and durability. Among inorganic products, lime-based treatments, although compatible, require a very high number of applications and still lack sufficient penetration and efficacy [5]. Silicate consolidants, in spite of being highly effective on silicate stones, are much less effective on carbonate stones, because in this case the bonding between the consolidant and the substrate is only physical [6], more specifically physico-chemical and does not involve covalent bonds.

To overcome the limitations of the available products, in 2011 calcium phosphates were proposed as a new class of materials for carbonate stones conservation $[7,8]$. The core idea is to form calcium phosphates, ideally hydroxyapatite $\left.\left(\mathrm{HAP}, \mathrm{Ca}_{10}\left(\mathrm{PO}_{4}\right)_{6}(\mathrm{OH})_{2}\right)\right)$, as the reaction product between the stone and an aqueous solution of a phosphate salt (typically diammonium hydrogen phosphate (DAP, $\left.\left(\mathrm{NH}_{4}\right)_{2} \mathrm{HPO}_{4}\right)$ ), according to the reaction [7]:

$$
\begin{aligned}
& 10 \mathrm{CaCO}_{3}+5\left(\mathrm{NH}_{4}\right)_{2} \mathrm{HPO}_{4} \rightarrow \mathrm{Ca}_{10}\left(\mathrm{PO}_{4}\right)_{6}(\mathrm{OH})_{2}+5\left(\mathrm{NH}_{4}\right)_{2} \mathrm{CO}_{3}+ \\
& 3 \mathrm{CO}_{2}+2 \mathrm{H}_{2} \mathrm{O}
\end{aligned}
$$

HAP was selected as a candidate to provide protection and consolidation to carbonate stones because: (i) it has a much lower solubility and slower dissolution rate than calcite, so

* Corresponding author: Enrico Sassoni, Tel. +39 0512090363, E-mail: enrico.sassoni2@unibo.it 
that if a continuous layer of HAP can be formed over a calcitic substrate, it is expected to inhibit its dissolution in water; (ii) it has a crystal structure and lattice parameters that are similar to those of calcite, so that the formation of a well adhering layer of HAP over calcite can be expected [79]. This paper proposes a review of work performed on this subject, with a particular focus on the contributions of the author in the context of the recently awarded RILEM Colonnetti medal.

\section{Treatment conditions}

Several studies have been dedicated through the years to the definition of the best treatment conditions, in terms of:

- nature of the phosphate precursor. Alongside DAP, also ammonium dihydrogen phosphate (ADP) and ammonium phosphate (AP) have been investigated as precursors $[9,10]$. However, since the main difference between these phosphate salts is their speciation in $\mathrm{PO}_{4}{ }^{3-}, \mathrm{HPO}_{4}{ }^{2-}$ and $\mathrm{H}_{2} \mathrm{PO}_{4}^{-}$ions and since the relative amount of these species actually depends on the solution $\mathrm{pH}$, the nature of the phosphate precursor is basically irrelevant, as long as the $\mathrm{pH}$ of the phosphate solution is controlled [9].

- $\mathrm{pH}$ of the phosphate solution. $\mathrm{pH}$ values ranging between 5 and 11 have been explored [9-11]. While $\mathrm{pH}<8$ was discarded (because soluble brushite forms in these conditions alongside HAP) [10], no practical benefit in terms of acid protection was obtained by increasing the $\mathrm{pH}>8$ [11], so in the end not adjusted DAP solutions at $\mathrm{pH}$ around 8 are usually adopted.

- concentration of the phosphate solution. DAP concentrations ranging from $0.1 \mathrm{M}[9,11]$ up to $3 \mathrm{M}$ (close to saturation) have been explored $[7,12]$. The motivation to use highly concentrated solution is that only a minor fraction $(<1 \%)$ of ions originated from DAP dissociation are $\mathrm{PO}_{4}{ }^{3-}$ ions (needed to form $\mathrm{HAP}$ ), whereas the largest part is in the form of $\mathrm{HPO}_{4}{ }^{2-}$ [9]. However, when highly concentrated DAP solutions are used, the formed calcium phosphate films tend to crack because of an excessive thickness. Additionally, some unreacted DAP might remain in the stone pores, so the use of lower concentrations is preferable [11]. A reduction in the DAP concentration and hence in the film tendency to crack was possible by adding ethanol to the solution, thanks to its weakening effect on the hydration shell of phosphate ions in solution [11,13].

- treatment duration. Reaction times ranging from 1 hour [9] up to 2 weeks [8] have been explored. In general, treating for at least 24 hours is recommended, to achieve a better coverage of marble surfaces [9] and a significant increase in mechanical properties (corresponding to $80 \%$ of the increase achieved after 8 days) [7].

- calcium ions addition and other ionic additions. With the aim of favoring and accelerating the formation of the calcium phosphate film, the possible addition of a calcium source to the DAP solution was investigated. With this, the required calcium ions do not need to dissolve from the substrate but are already available in the solution [8]. Among the several calcium sources investigated $\left(\mathrm{CaCl}_{2}[8,9], \mathrm{Ca}\left(\mathrm{NO}_{3}\right)_{2}[8], \mathrm{Ca}(\mathrm{OH})_{2}[14]\right.$, calcium gluconate [9], calcium formate [9] and nanolimes [15]), the addition of $\mathrm{CaCl}_{2}$ in molar ratio of 1:1000 to the DAP concentration has been found to provide the best results, in terms of coverage of marble surface and rate of film formation [9]. The addition of other ions (i.e. strontium [9], magnesium [9] and aluminum [11]) to the DAP solution has been investigated as well, with the aim of doping the HAP crystal structure so as to further improve the match with calcite in terms of lattice parameters. However, none addition proved to provide a significant benefit.

A very important aspect that needs careful evaluation is the nature of the calcium phosphate phases formed after the treatment $[7,16]$. Indeed, during the reaction reported above, carbonate ions can partly replace phosphate and hydroxyl ions, thus leading to the formation of carbonated HAP, that has a higher solubility than stoichiometric HAP [7]. Moreover, depending on the treatment conditions $(\mathrm{pH}$, reaction time, ionic additions) several different calcium phosphate phases may form alongside HAP, these phases differing in terms of $\mathrm{Ca} / \mathrm{P}$ ratio and solubility [17]. As long as phases with a solubility lower than calcite (although higher than HAP) are formed, the treatment is still expected to be successful, especially if the presence of these phases is linked to an improvement in the completeness and/or density of the film. For instance, the addition of $\mathrm{CaCl}_{2}$ to the DAP solution causes the formation of octacalcium phosphate (OCP, $\left.\mathrm{Ca}_{8}\left(\mathrm{PO}_{4}\right)_{6} \mathrm{H}_{2} \cdot 5 \mathrm{H}_{2} \mathrm{O}\right)$ alongside HAP [9]. Even if OCP has a higher solubility than HAP, the resulting acid protection was found to be improved, because OCP allows a more complete coating to be formed [17]. Similarly, when ethanol was added to the DAP solution, the calcium phosphate film was found to be mainly composed of OCP, but also in this case a beneficial effect was found, because ethanol addition prevents crack and pore formation [13]. On the contrary, when phases with solubility higher than calcite are formed (e.g., brushite), no positive outcome can be expected from the treatment, because any protective and consolidating effect will disappear after contact with rain [10].

\section{Protection}

For a treatment to be successful in providing protection against dissolution in rain, the film formed over the stone surface needs to be continuous (i.e. no bare areas should remain after treatment), crack-free and pore-free (because cracks and pores would allow water to penetrate through the coating and reach the substrate, thus triggering its dissolution). 
Among the formulations tested through the years, the following ones (all applied for 24 hours) have provided the best results:

- aqueous solution containing $1 \mathrm{M}$ DAP and $1 \mathrm{mM} \mathrm{CaCl}$. Compared to treatment with $1 \mathrm{M}$ DAP alone, this formulation achieves a better surface coverage [9] and a better acid protection [18]. Indeed, in spite of the formation of OCP alongside HAP (which was the only phase formed using 1 M DAP [9]), an almost complete surface coverage was obtained, as illustrated in Figure 1. This allowed to achieve a significant acid protection: compared to the untreated reference, this formulation led to a reduction in the acid attack rate by about $40 \%$ [18]. The efficacy was not higher (as would be expected from theoretical considerations) because a few bare areas remain, the film exhibits some micro-cracks (likely developed during drying) and includes inherent porosity $[13,18]$.

- water-ethanol (90-10 vol\%) solution containing $0.1 \mathrm{M}$ DAP and $0.1 \mathrm{mM} \mathrm{CaCl}$. Thanks to the ethanol addition, it was possible to reduce the DAP concentration, thus preventing micro-cracks formation [11]. Moreover, the ethanol addition allowed to form a much denser coating compared to the use of $1 \mathrm{M} \mathrm{DAP}$ and $1 \mathrm{mM} \mathrm{CaCl}_{2}$ [13], as illustrated in Figure 2. As already mentioned, this was possible thanks to the beneficial effect of the ethanol molecules on the phosphate ions in the DAP solution [13]. Thanks to the absence of micro-cracks and pores, this formulation allows to achieve a better acid protection than the previous one (unpublished results). However, few areas with incomplete or no coverage are still present, which is thought to be a consequence of the more or less favorable orientation of calcite grains over which the film develops.

\section{Consolidation}

For a treatment to be successful in consolidating weathered stone, the newly formed phases must be able to seal the tip of the micro-cracks among the stone grains $[6,19]$. Unlike the case of protecting layers, in this case the fact that the formed calcium phosphate film completely covers the grain surface and is pore-free is not as essential, provided that new phases form at the crack tip. Anyway, formation of a cracked layer should be avoided, because the cracks in the consolidant may be detrimental if they propagate through the grain boundaries [6]. Moreover, the treatment must cause no or limited alterations in stone color, open porosity and pore size distribution, water and water vapor transport properties, compared to the non-treated surrounding stone [19]. Finally, the durability of treated stone to the weathering processes affecting it (typically, heating-cooling cycles in the case of marble, ice and salt crystallization cycles in the case of porous limestone) must not be worsened but rather hopefully improved [20].

Also in this case, several formulations (all applied for 24 hours) have been proposed and tested through the years:
- aqueous solution containing $1 \mathrm{M}$ DAP and $1 \mathrm{mM} \mathrm{CaCl}$. Similarly to the case of marble protection, this formulation was found to be more effective than the formulation involving treatment with $1 \mathrm{M}$ DAP alone. Whereas treating artificially weathered limestone with a $1 \mathrm{M}$ DAP solution led to a dynamic elastic modulus increase $\Delta E_{d}=+60 \%$ [7], by also adding $1 \mathrm{mM} \mathrm{CaCl}_{2}$ to the solution the mechanical improvement was up to $\Delta E_{d}$ $=+110 \%$ [21]. In the case of artificially weathered marble, increases in $E_{d}$ up to $+150 \%$ were obtained.

- water-ethanol (90-10 vol\%) solution containing $0.1 \mathrm{M}$ DAP and $0.1 \mathrm{mM} \mathrm{CaCl}_{2}$. In the case of marble artificially decayed so as to produce an $E_{d}$ decrease of $40 \%$, this formulation was able to increase the $E_{d}$ up to $88 \%$ of its initial level after a first treatment and to completely restore $E_{d}$ after a second treatment [13]. In spite of being slightly less effective than the previous formulation, this one has the advantage of being able to provide a better acid protection, in those cases when both consolidation and protection are needed.
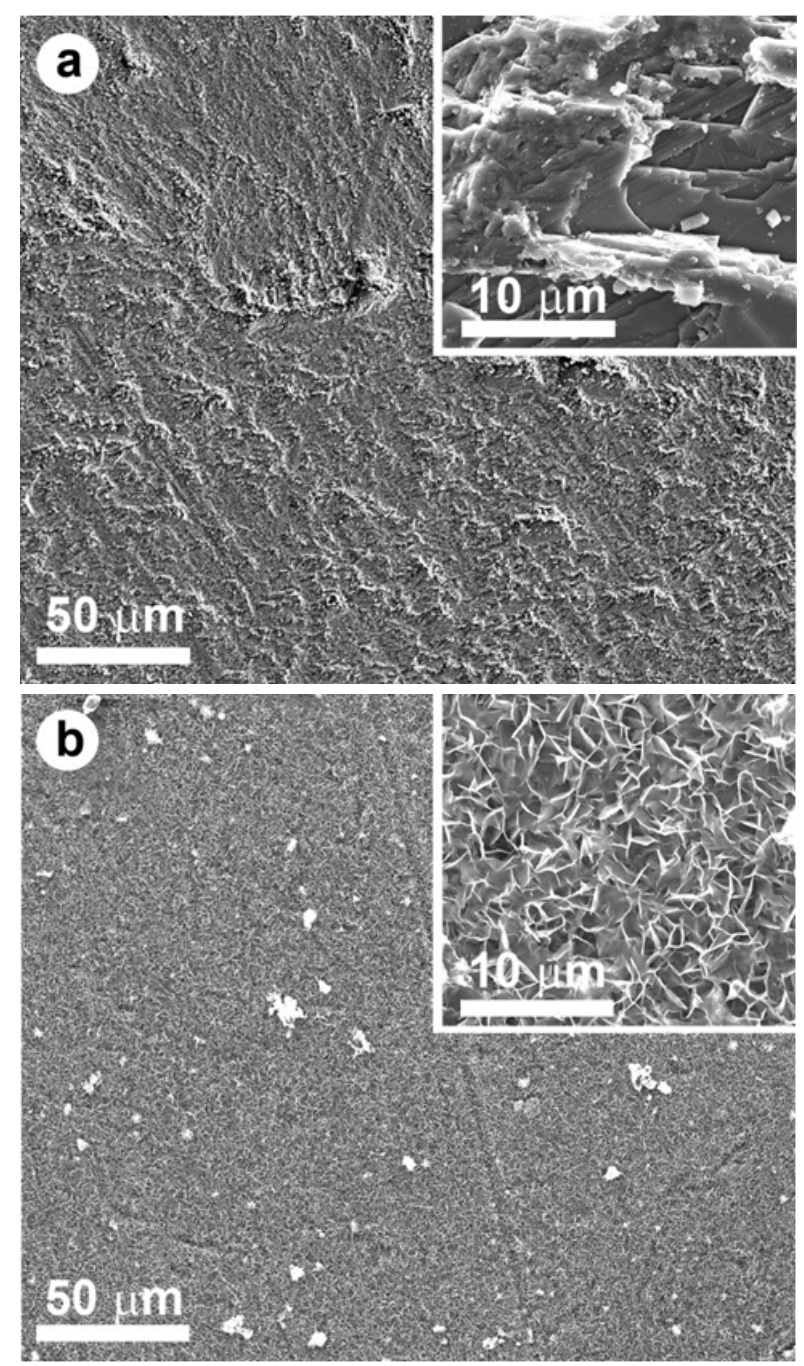

Figure 1. SEM images of Carrara marble surface before (a) and after (b) treatment with a $1 \mathrm{M} \mathrm{DAP}$ and $1 \mathrm{mM} \mathrm{CaCl}$ solution. Continuous coating of marble surface with a new calcium phosphate coating (composed of both HAP and OCP) can be observed after treatment (b). 

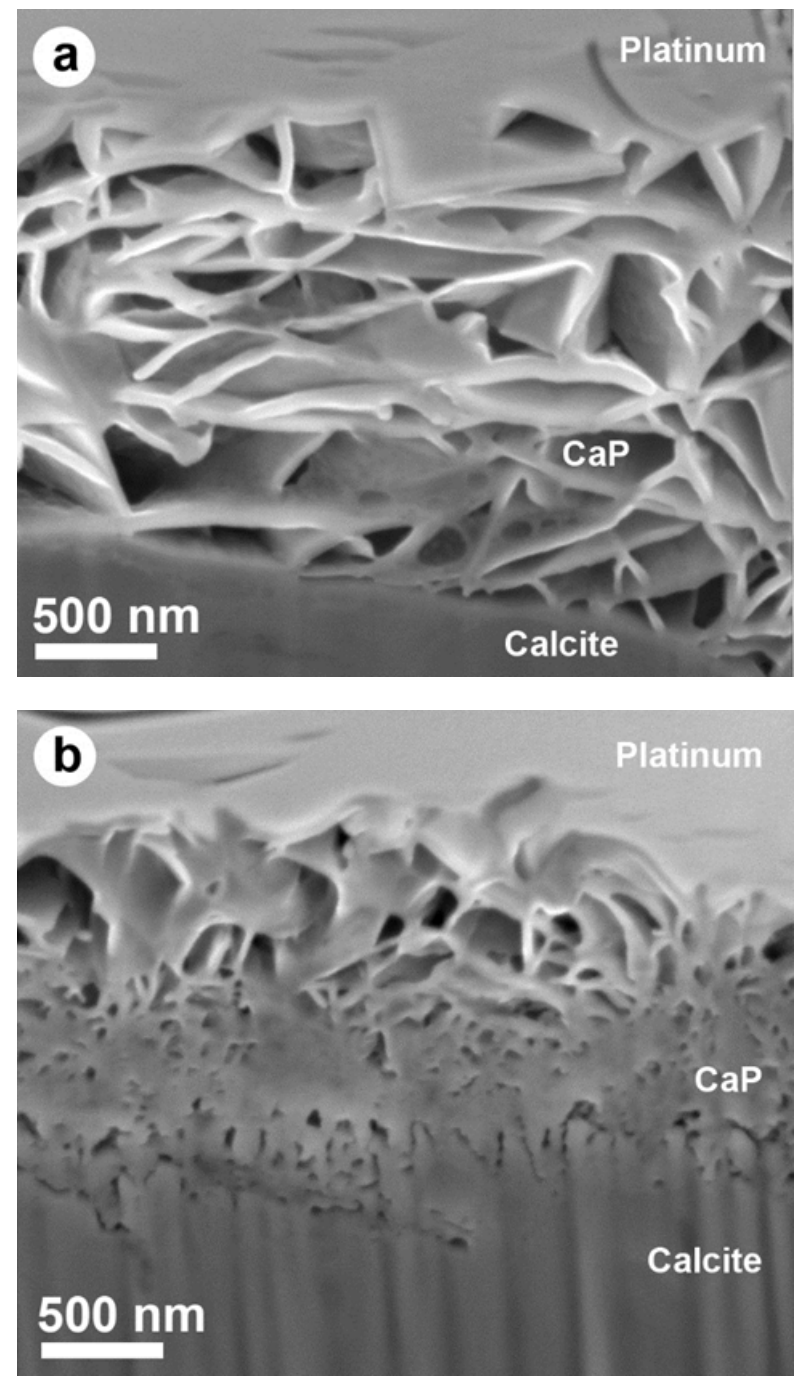

Figure 2. SEM-FIB images of the calcium phosphate film formed over Carrara marble by treatment with a $1 \mathrm{M} \mathrm{DAP}$ and $1 \mathrm{mM} \mathrm{CaCl} 2$ solution (a) and with a $0.1 \mathrm{M} \mathrm{DAP}$ and $0.1 \mathrm{mM} \mathrm{CaCl}_{2}$ solution also containing 10 vol\% ethanol (b). The beneficial effect of ethanol on the density of the coating can be observed in (b).

- aqueous solution of 3 M DAP, followed (after drying) by a limewater poultice. This formulation is the only one involving a second step after application of the DAP solution, namely the application of a poultice of so-called limewater (i.e. a saturated solution of $\mathrm{Ca}(\mathrm{OH})_{2}$ ). The aim of this second step is twofold: (i) during the poultice application, unreacted DAP can dissolve and react with calcium ions present in the solution, so that further HAP formation can take place; (ii) during drying of the poultice in contact with the stone, still unreacted DAP is transported through the surface and finally crystallizes in the poultice, so that no residues are left in the stone [22]. This formulation has been found to be able to penetrate deep into the substrate $(20 \mathrm{~mm}$ in marble [12], $25 \mathrm{~mm}$ in limestone [22]) and provide a remarkable consolidating action $\left(\Delta E_{d}=+500 \%\right.$ in marble [12] and $\Delta E_{d}$ $=+50 \%$ in limestone [19]). In both stone types, the original mechanical properties are fully restored after treatment. This formulation has been thoroughly characterized, in terms of compatibility and durability of treated stone, in the case of both marble and limestone. In terms of chromatic alterations, only minor color changes $\Delta E^{*}$ have been found $\left(\Delta E^{*}=2\right.$ on marble [12] and $\Delta E^{*}=3$ on limestone [19]), both below the threshold commonly accepted for consolidating treatments $\left(\Delta E^{*}=\right.$ $5)$. On both lithotypes, only a very limited alteration in open porosity has been found $[12,19]$. In the case of limestone, some alteration in the pore size distribution in the range of 0.01-0.2 $\mu \mathrm{m}$ pores has been detected [19]. Considering the potential risk connected to an increase in the number of thin pores (because the smaller the pore, the higher the ice and salt crystallization pressure [3]), specific durability tests have been carried out. Thanks to the improved mechanical properties and the limited alterations in microstructure, HAP-treated limestone resisted ice and salt crystallization tests better than the untreated stone, undergoing only small decreases in dynamic elastic modulus $E_{d}$ and tensile strength $\sigma_{\mathrm{t}}\left(\Delta E_{d}=-5 \%\right.$ and $\Delta \sigma_{\mathrm{t}}=-6 \%$ after 70 freeze-thaw cycles, $\Delta E_{d}=0 \%$ and $\Delta \sigma_{t}=-15 \%$ after 5 salt crystallization cycles and desalination) [20]. Notably, the HAP-treated stone survived the durability tests better than samples treated with a commercial ethyl silicate, analyzed for comparison's sake [20]. The good performance of the HAP-treated limestone also descends from the fact that (unlike the case of ethyl silicate) stone remains hydrophilic after the HAP-treatment [19]. In this way, possible risks connected to the formation of a hydrophobic layer (that may detach if a water source is present behind it) are prevented [20]. In the case of marble, for which the major deterioration cause is microcracking induced by temperature variations, the thermal behavior of HAP-treated samples has been characterized [23]. Dilatometric tests showed that, after treatment, the thermal expansion coefficient is increased (because of the re-established cohesion between grains), but the residual strain at the end of the cycles is lower than for the unweathered reference. Therefore, no worsening of the thermal behavior of HAP-treated marble is expected [23].

\section{Conclusions}

Calcium phosphates, formed by reaction of carbonate stones with an aqueous phosphate solution (possibly also containing $\mathrm{CaCl}_{2}$ as a calcium source and ethanol), have shown a great potential so far. They have proven to be able to provide marble with significant protection against dissolution in rain and to completely restore mechanical properties of weathered marble and limestone.

Compared to the ammonium oxalate treatment, the phosphate treatment has the advantage of a much higher penetration depth (up to $20 \mathrm{~mm}$, whereas calcium oxalate mainly forms in the first $0-2 \mathrm{~mm}$ from the treated surface) and, at least theoretically, the much lower solubility of HAP and $\mathrm{OCP}$, compared to calcium oxalate. However, for the phosphate treatment to be as protective as theoretical 
considerations suggest, it is essential to achieve a complete coverage of the substrate with a crack-free and non-porous film. Significant advances have been achieved so far by introducing ethanol into the DAP solution, but further improvements are possible, for instance by using a more effective organic solvent.

Compared to ethyl silicate, the phosphate treatment has the first advantage of being effective after just 24 hours, while at least 4 weeks of curing are necessary for ethyl silicate. Moreover, stone treated with the DAP solution remains hydrophilic, whereas after ethyl silicate application stone remains hydrophobic until hydrolysis-condensation reactions are completed (which may take up to 6 months [6]). During this period, issues related to the stone hydrophobicity may arise (e.g. detachment of the treated layer, if a water source is present behind it), while no such risk is present for DAPtreated stone. Compared to ethyl silicate, the phosphate treatment also causes lower alterations in color (especially in marble) and pore size distribution, with a consequent better resistance to ice and salt crystallization cycles. The phosphate treatment also has the advantage of not involving any toxic chemical, which is positive for both the operator and the environment [19].

Considering its potential, some pilot applications of the phosphate treatment to real decayed artifacts and real case studies have been carried [12,24,25]. Moreover, an increasing number of studies is dealing with the possible application of the phosphate treatment to additional substrates, such as sandstones [26], gypsum [27], archaeological wall paintings [28], and archaeological bones [29].

\section{Acknowledgements}

I would like to thank Prof. George W. Scherer (Princeton University, USA) for giving me the chance to work with him on the calcium phosphate project since 2010 and for teaching me so many things about the specific subject and materials science in general all through these years. I would also like to thank Dr. Elisa Franzoni and Dr. Gabriela Graziani (University of Bologna, Italy) and Dr. Sonia Naidu (SaintGobain, France) for collaborating on this topic since the beginning, for the fruitful discussion and the precious help. I would like to thank RILEM for awarding me one the prestigious Gustavo Colonnetti Medals for 2017. I would also like to acknowledge funding from the European Union's Horizon 2020 research and innovation program under the Marie Skłodowska-Curie grant agreement N. 655239 (HAP4MARBLE project, "Multi-functionalization of hydroxyapatite for restoration and preventive conservation of marble artworks").

\section{References}

[1] K. Lal Gauri, J.K. Bandyopadhyay, Carbonate Stone, Chemical behavior, durability and conservation. Wiley, New York, 1999.

[2] S. Siegesmund, K. Ullemeyer, T. Weiss, E.K. Tschegg, Physical weathering of marbles caused by anisotropic thermal expansion. Int J Earth Sci, (2000) 89: 170-182. https://doi.org/10.1007/s005310050324
[3] G.W. Scherer, Stress from crystallization of salt. Cem Concr Res (2004) 34: 1613-1624. https://doi.org/10.1016/j.cemconres.2003.12.034

[4] P. Baglioni, E. Carretti, D. Chelazzi, Nanomaterials in art conservation. Nature Nanotechnology (2015) 10: 287-290. https://doi.org/10.1038/nnano.2015.38

[5] E. Hansen, E. Dohene, J. Fidler, J. Larson, B. Martin, M. Matteini, C. Rodriguez-Navarro, E.S. Pardo, C. Price, A. de Tagle, J. M. Teutonico, $\mathrm{N}$. Weiss, A review of selected inorganic consolidants and protective treatments for porous calcareous materials. Reviews in Conservation (2003) 4: 13-25.

[6] G.W. Scherer, G.S. Wheeler, Silicate consolidants for stone. Key Eng Mater (2009) 391: 1-25. https://doi.org/10.4028/www.scientific.net/KEM.391.1

[7] E. Sassoni, S. Naidu, G.W. Scherer, The use of hydroxyapatite as a new inorganic consolidant for damaged carbonate stones. J Cult Herit, (2011) 12: 346-355. https://doi.org/10.1016/j.culher.2011.02.005

[8] S. Naidu, E. Sassoni, G.W. Scherer, New treatment for corrosionresistant coatings for marble and consolidation of limestone, in Stefanaggi M., Vergès-Belmin V. (Eds), "Jardins de Pierres Conservation of stone in Parks, Gardens and Cemeteries", Paris (F) 22-24 June 2011, p. 289-294.

[9] S. Naidu, G.W. Scherer, Nucleation, growth and evolution of calcium phosphate films on calcite. J Colloid Interface Sci (2014) 435: 128137. https://doi.org/10.1016/j.jcis.2014.08.018

[10] M. Matteini, S. Rescic, F. Fratini, G. Botticelli, Ammonium phosphates as consolidating agents for carbonatic stone materials used in architecture and cultural heritage: Preliminary research, Int J Archit Herit, (2011) 5: 717-736. https://doi.org/10.1080/15583058.2010.495445

[11] G. Graziani, E. Sassoni, E. Franzoni, G.W. Scherer, Hydroxyapatite coatings for marble protection: Optimization of calcite covering and acid resistance, Appl Surf Sci (2016) 368: 241-257. https://doi.org/10.1016/i.apsusc.2016.01.202

[12] E. Sassoni, G. Graziani, E. Franzoni, Repair of sugaring marble by ammonium phosphate: comparison with ethyl silicate and ammonium oxalate and pilot application to historic artifact, Mater Des (2015) 88: 1145-1157. https://doi.org/10.1016/i.matdes.2015.09.101

[13] E. Sassoni, G. Graziani, E. Franzoni, G.W. Scherer, Some recent findings on marble conservation by aqueous solutions of diammonium hydrogen phosphate. MRS Advances (2017) 2: 20212026. https://doi.org/10.1557/adv.2017.45

[14] E. Sassoni, E. Franzoni, G.W. Scherer, S. Naidu, Consolidation of a porous limestone by means of a new treatment based on hydroxyapatite. 12th International Congress on Deterioration and Conservation of Stone, Columbia University, New York City (USA), 22-26 October 2012, p. 1-11. http://iscs.icomos.org/pdffiles/NewYorkConf/sassetal.pdf

[15] F. Yang, B. Zhang, Y. Liu, W. Guofeng, H. Zhang, W. Cheng, Z. Xu, Biomimic conservation of weathered calcareous stones by apatite. New J Chem (2011) 35: 887-892. https://doi.org/10.1039/c0nj00783h

[16] E. Possenti, C. Colombo, D. Bersani, M. Bertasa, A. Botteon, C. Conti, P.P. Lottici, M. Realini, New insight on the interaction of diammonium hydrogenphosphate conservation treatment with carbonatic substrates: A multi-analytical approach. Microchemical J (2016) 127: 79-86. https://doi.org/10.1016/i.microc.2016.02.008

[17] S.V. Dorozhkin, Calcium orthophosphates. Biomatter (2011) 1: 121164. https://doi.org/10.4161/biom.18790

[18] S. Naidu, J. Blair, G.W. Scherer, Acid-resistant coatings on marble. J Am Ceram Soc 99 (2016) 3421-3428. https://doi.org/10.1111/jace.14355

[19] E. Sassoni, G. Graziani, E. Franzoni, An innovative phosphate-based consolidant for limestone. Part 1: Effectiveness and compatibility in comparison with ethyl silicate. Constr Build Mater (2016) 102: 918930. https://doi.org/10.1016/j.conbuildmat.2015.04.026

[20] E. Sassoni, G. Graziani, E. Franzoni, An innovative phosphate-based consolidant for limestone. Part 2: Durability in comparison with ethyl silicate. Constr Build Mater (2016) 102: 931-942. https://doi.org/10.1016/j.conbuildmat.2015.10.202

[21] S. Naidu, C. Liu, G.W. Scherer, New techniques in limestone consolidation: Hydroxyapatite-based consolidant and the acceleration of hydrolysis of silicate-based consolidants. J Cult Herit (2015) 16: 94-101. https://doi.org/10.1016/j.culher.2014.01.001

[22] E. Franzoni, E. Sassoni, G. Graziani, Brushing, poultice or immersion? Role of the application technique on the performance of a novel 
hydroxyapatite-based consolidating treatment for limestone. J Cult Herit (2015) 16: 173-184.

https://doi.org/10.1016/j.culher.2014.05.009

[23] E. Sassoni, G. Graziani, G. Ridolfi, M.C. Bignozzi, Franzoni E., Thermal behavior of Carrara marble after consolidation by ammonium phosphate, ammonium oxalate and ethyl silicate. Mater Des (2017) 120: 345-353. https://doi.org/10.1016/.j.matdes.2017.02.040

[24] E. Sassoni, E. Franzoni, Sugaring marble in the Monumental Cemetery in Bologna (Italy): characterization of naturally and artificially weathered samples and first results of consolidation by hydroxyapatite. Appl Phys A (2014) 117: 1893-1906. https://doi.org/10.1007/s00339-014-8629-3

[25] X. Ma, M. Balonis, H. Pasco, M. Toumazou, D. Counts, I. Kakoulli, Evaluation of hydroxyapatite effects for the consolidation of a Hellenistic-Roman rock-cut chamber tomb at Athienou-Malloura in Cyprus. Constr Build Mater (2017) 150: 333-344. https://doi.org/10.1016/i.conbuildmat.2017.06.012

[26] E. Sassoni, E. Franzoni, B. Pigino, G.W. Scherer, S. Naidu, Consolidation of calcareous and siliceous sandstones by hydroxyapatite: comparison with a TEOS-based consolidant J Cult Herit (2013) 14S: e103-e108.

https://doi.org/10.1016/j.culher.2012.11.029

[27] E. Molina, L. Rueda-Quero, D. Benavente, A. Burgos-Cara, E. RuizAgudo, G. Cultrone, Gypsum crust as a source of calcium for the consolidation of carbonate stones using a calcium phosphate-based consolidant. Constr Build Mater (2017) 143: 298-311. https://doi.org/10.1016/j.conbuildmat.2017.03.155

[28] M. Balonis-Sant, X. Ma, I. Kakoulli, Preliminary Results on Biomimetic Methods Based on Soluble Ammonium Phosphate Precursors for the Consolidation of Archaeological Wall Paintings, Archaeological Chemistry VIII. Washington DC: American Chemical Society, ACS Symposium Series, 2013, pp. 420-47

[29] North, M. Balonis, I. Kakoulli, Biomimetic hydroxyapatite as a new consolidating agent for archaeological boneStud Conserv (2016) 61: 146-161. https://doi.org/10.1179/2047058415Y.0000000020 